\title{
Real-time Geographic Information System (GIS) for Monitoring the Area of Potential Water Level Using Rule Based System
}

\author{
Wirdah Anugrah ${ }^{1, *}$, Suryono Suryono ${ }^{1,2}$, and Jatmiko Endro Suseno ${ }^{2}$ \\ ${ }^{1}$ Magister of Information System, Diponegoro University, Semarang - Indonesia \\ ${ }^{2}$ Physics Department of Science and Mathematics Faculty, Diponegoro University, Semarang - Indonesia
}

\begin{abstract}
Management of water resources based on Geographic Information System can provide substantial benefits to water availability settings. Monitoring the potential water level is needed in the development sector, agriculture, energy and others. In this research is developed water resource information system using real-time Geographic Information System concept for monitoring the potential water level of web based area by applying rule based system method. GIS consists of hardware, software, and database. Based on the web-based GIS architecture, this study uses a set of computer that are connected to the network, run on the Apache web server and PHP programming language using MySQL database. The Ultrasound Wireless Sensor System is used as a water level data input. It also includes time and geographic location information. This GIS maps the five sensor locations. GIS is processed through a rule based system to determine the level of potential water level of the area. Water level monitoring information result can be displayed on thematic maps by overlaying more than one layer, and also generating information in the form of tables from the database, as well as graphs are based on the timing of events and the water level values.
\end{abstract}

\section{Introduction}

Management of water recourses which is carried out in real time is urgently needed due to its benefit in irrigation, food supply, transportation, recreation, climate, fishery, farms, energy resources, natural resources and many others. An error in managing the water resources can trigger disasters such as floods, tsunami, and landslides, so that it needs a system to monitor the level of water in a certain area to avoid those disasters. The information of Water Resources Management as a real-time monitoring will be useful to any departments that need water resource management and the society. The main concept of real-time water resource information system is to give any accurate and informative [1].

The monitoring process using rule-based system is very easy to be applied so that the system can work in a smart way [2]. Rule-based system is used in the region with small scale problems, and it can suit the data available. The available data will be processed in the monitoring system by using Rule-Based System. Rulebased system is applied in storing and manipulating the information to interpret the condition as effective and easy to understand so that ru-based system is often used in implementation handmade smart reviews and researches. The rule-based system is mostly applied in expert system using rules to have deductive conclusion or alternative choices, written in if-then style.

Based on the fact on the field, the management of water resources faces problems on the expensiveness of the instruments, real-time, data continuum, memory capacity, limitation of the human resource, the wide cope of the area, area disturbance, maintenance, calibration and spare part for any malfunctions. Monitoring water real-timely is based on computerized communication network and database with sophisticating monitoring instruments of a sensor to bring up online real-time monitoring [3].

From the explanation above, if monitoring the level of water is not carried out real-timely, it will give negative impacts, such as flood happening mostly in lowland. The information from real-time monitoring system can give predictive description about what is going to happen and what action taken will be more precise. The use of rule-based system method in the monitoring model of potential water level in a certain spotted area which is done real-timely, will be displayed in a form of GIS map. Using data of water level, time, geographical location and coordinate spot, potential water level monitoring can be done easily. The output of the system of using the result can be in form of web, application for smartphone or even as the computer desktop. It discusses any location in 5 spot, so it can represents relevant monitoring result with the location

*Corresponding author: wirdahanugrah1989@gmail.com 
based system. GIS will give easy assess to its users or decision makers to make any policies. GIS has been widely used to assess any information about a certain location.

\section{Geographic Information System (GIS)}

GIS is an information system that shows information in a form of geographical map as interface data. GIS is set of concepts of layers and its relations [4]. The analyse used in GIS is overlay analyse as data integrated process among the different layers. The analyse needs more than one layer which is physically staged and will be analyzed visually. GIS also needs spatial analyse as a group of techniques which can be used as the data processing of GIS [5]. GIS is developed using internet technology called web-based GIS as shown in Figure 1.

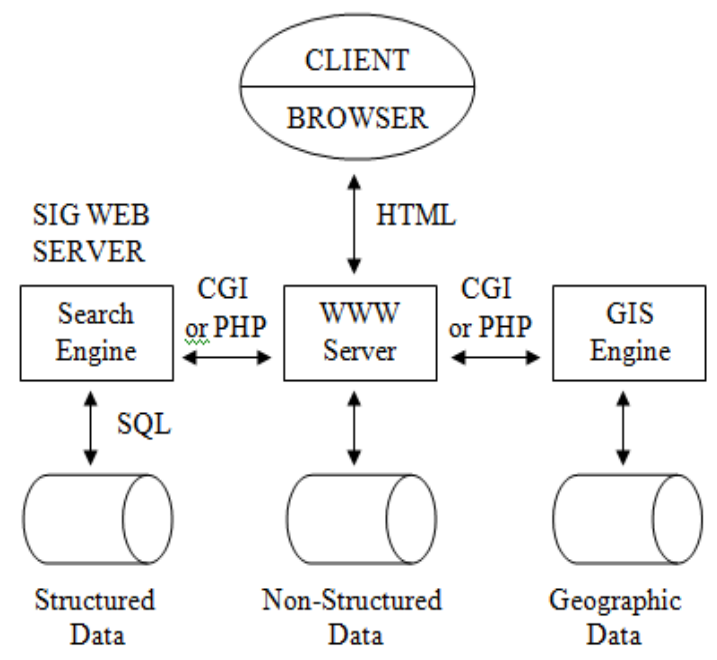

Fig. 1. Architecture of Web-based GIS [6]

Architecture of web-based GIS is a client-server structure. The use of this structure is in order to make easy access to the data and efficient in displaying information as it reduces the use of paper based data processing. This GIS structure consist of some main components, such as :

1. Browser as the media for the clients. They can use Mozilla Firefox.

2. Web server as the data provider that can be operated by any operator to share data in web, the web server use dis Apache.

3. Programme language used to process any request from server is PHP or CGI

4. The internet is used as the communication media between server and clients.

5. Engine used to process the structured and non structure data or geographycal data is map server. Map server is to read mapfile, map data and other dataas file.shp which produces map in .png.

6. Structured data is in form of database as the data storage in form of MySQL.

\section{Rule Based System Method}

Rule based system consists of if-then rules, a group of data and an interpreter as the controller of the rules applied in providing facts. Statements used of if-then rules to formulate the conditional reports consist of complete knowledge. Single If-then rules assume 'if $\mathrm{x}$ is A so $y$ is B' and if is a part of ' $\mathrm{x}$ rules is A it is called premise, and part of command ' $\mathrm{y}$ is $\mathrm{B}$ ' is called conclusion [7]. Rule based system is a relative simple model that can be suited to many problems. Rule based system is a part of Artificial Intelligent (AI). Rule based system can only be used to problems with science and rules and in the rather small area [8]. Rule has distinctive form:

\section{If $<$ conditions $>$ then $<$ conclusion $>$;}

Rule based method fits to application domain which is easy, understandable, complete, small cope area and limited [9].

\section{Research Methodology}

The research carried out has stages that are done with the aim to get the maximum result done by using System Development Life Cycle (SDLC) development method with waterfall method, including system planning, system requirement analysis, system design, system implementation, system test, and System maintenance [9].

\subsection{Planning of System}

The first stage of planning is the activities undertaken before the research took place is the stages in conducting the collection of literature such as international and national journals that fit and support the research topic, as well as articles relevant to the research topic. Observations made include the contemporary problems, the current method will be applied as inputs in the design of the information system to be built.

\subsection{Analyzing of System Requirement}

Stages of system requirement analysis are the steps to determine the required variables such as water level data, coordinate point, time data, location data, and existing layers such as, river boundary map, Watershed (DAS) map, and regional map Flood with the system to be built. The system requirements analysis also addresses some of the needs and or requirements related to input, process, and output, as follows:

1. Input

Is a data input process in the form of a series of activities performed by administrators and users (local government and the general public). The administrator (manager) manages the web of geographic information systems and facilitates added data, modify and delete. The data input is in the form of water level data acquisition, time, and location 
coordinate point. Users (local governments and the general public) can only view information such as: maps, water level potential status, altitude values, sensor locations, and graphs based on time and water levels.

2. Process

Represents processes that run on geographic information systems for monitoring the potential of the water level of the region using a rule based system with the step of making maps and overlays taken from the google map API. Creation of coordinate points of location by performing coordinate input in the form of latitude and longitude of locations with 5 sensors will be sent to the server to be stored in the database.

3. Output

The output obtained is information in the form of maps, water level potential status, height values, sensor location, and graphs based on the time and value of water level that have been processed by using rule based system.

The analysis used in the Geographic Information System in monitoring the potential of the regional water level is spatial analysis. Analyzes require more than one layer to be physically compiled in order to be visually analyzed. Layers used in this GIS, namely: Google map as the base map, the sensor is a type of point layer, watershed, river border, and flooded areas in the form of polygon-type layer, and non-spatial data in the form of water level data in meters. Spatial analysis is done by calculating area based on spatial data (coordinate point). Spatial analysis in this study is the calculation of the area that appears for each polygon that is clicked. The method of rule base system is used in monitoring the potential of the water level of the area by applying the existing rules based on the regulation of the Head of National Disaster Management Agency Number 02 of 2012 on General Guidelines for Disaster Risk Assessment.

In the broad calculations that appear for each polygon that is clicked, as in the following calculation:

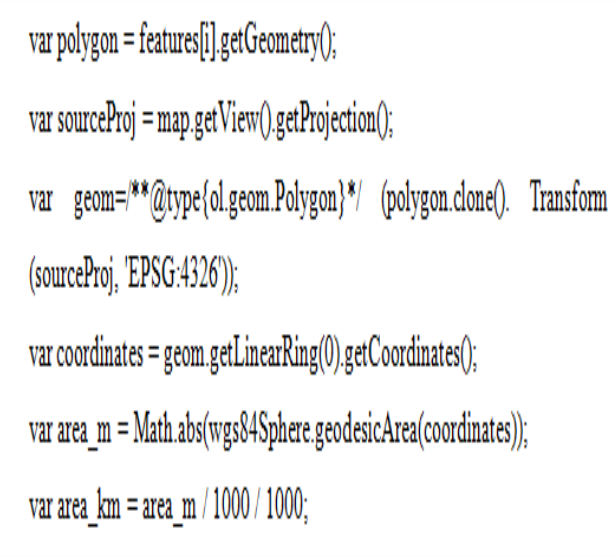

\subsection{Designing of System}

Development of information systems begins with the determination of input (input) to be used, then proceed with the process as the implementation of the applied method and ends with the form of output (output) to be displayed. The design of information systems as shown Figure 2.

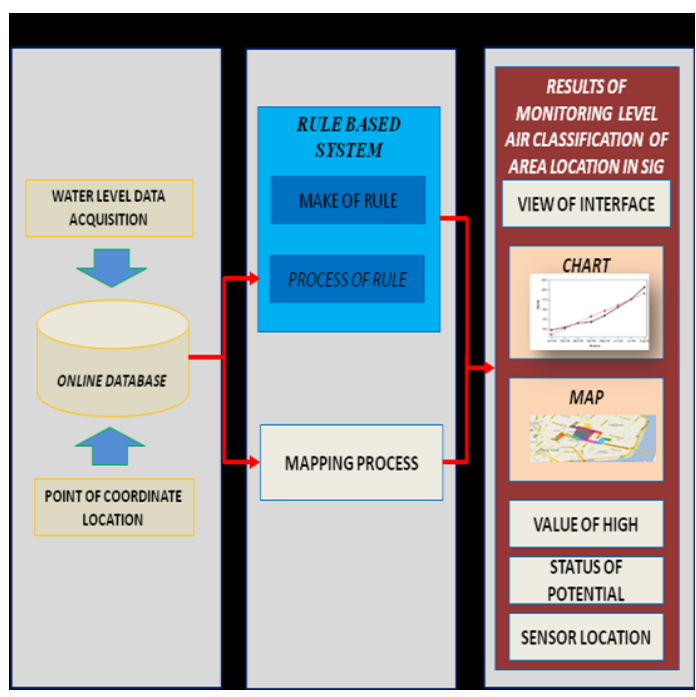

Fig.2. Framework of information system

As for the description of the flow of water level data acquisition starts from the data acquisition process using the sensor, then storage of historical data in the local database (local database) in the microcontroller, then by utilizing the request http (http request) and modem connection of historical data is sent to the web Server. The internet-connected web server accepts and stores all historical data of water level levels sent periodically from those sensors in the database (online database). Data stored on the database in the network (online database) is used as an analysis material as shown in Figure 3.

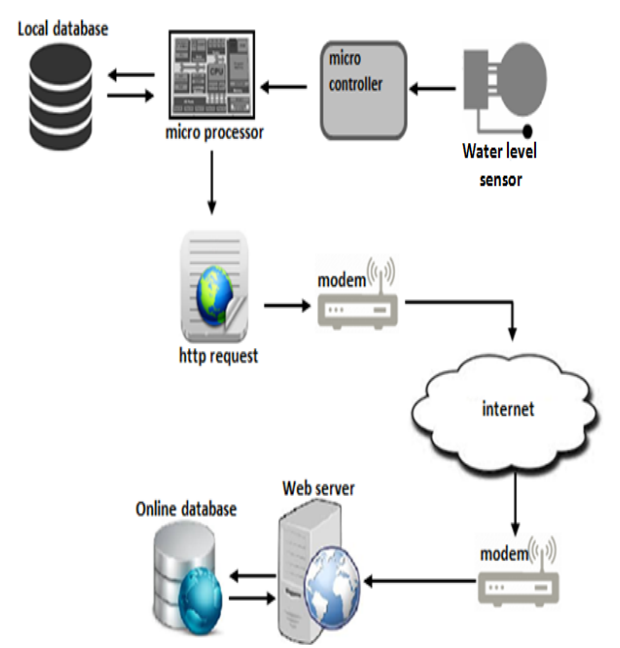

Figure 3. The process of acquisition and transmission of water level sensor data

\subsection{Implementing of System}

Implementation stage is the stage of programming. At this stage will implement the information system by 
applying the rule-based system method used in the process of monitoring the potential water level of the area into the application to be built using PHP and MySQL, then displayed in the form of Geographic Information System.

\subsection{Coding of System}

In the real-time application of Geographic Information System application for monitoring the potential of the water level of this area, to prove that the system can run well the testing method used is black box testing which means the test process is displayed in the form of a table which describes the description of test, initial precondition, Test procedures, input data used, expected outputs, evaluation criteria, results obtained from the test and the final conclusion of the test.

The result of GIS software testing that has been done shows that the system runs in accordance with the functions required by the user (user) and admin (manager). Admin can enter water level data that has been processed with rule based system also to be able to add, change, and delete data, then system can monitor potential of level air in accordance with water level data, so that obtained information accurate according to user requirement presented in the form map. And the information obtained also in the form of related layers, water level potential status, height values, sensor location, and graphs based on the time of occurrence and value of water level. The above is the advantage of this GIS application program, the presentation of information more clear and easy to understand and always updated and real-time.

\section{Results and Discussion}

The results of the implementation are generally described with screenshot images from the GIS in real time for monitoring the potential of the water level of the region by using the rule based system method. Under the following explanation there are some images of the results of the system screenshot. The results of system implementation on user pages (Local Government and Public) can only see information in the form of: maps, related layers, water level potential status, height values, sensor location, polygon area, and graphs based on time and water level. If one of the sensors is clicked it will display a description of the object identification indicating that the sensor is located on one of the existing layers, as shown Figure 4.

Users (Local Government and Public) can also see graphs from the monitoring results of potential water levels in the area. Monitoring results are shown in graphical form based on time and water level, as shown in Figure 5. In addition to the implementation results of the system there are also screenshot implementation of the GIS database. Implementation of the program by using PHP which is a programming language used for the creation of web applications with MySQL database, as shown Figure 6.

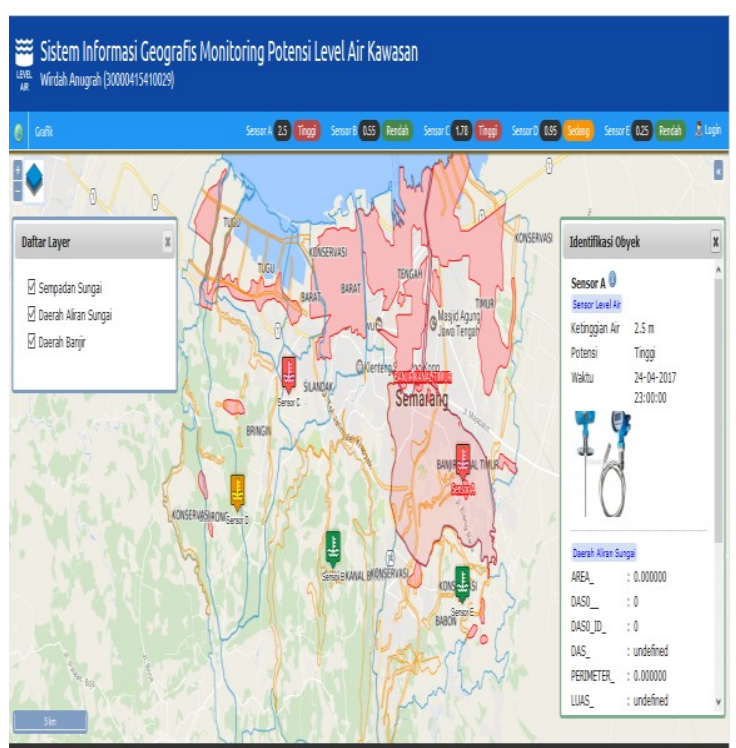

Fig. 4. Page of description full user

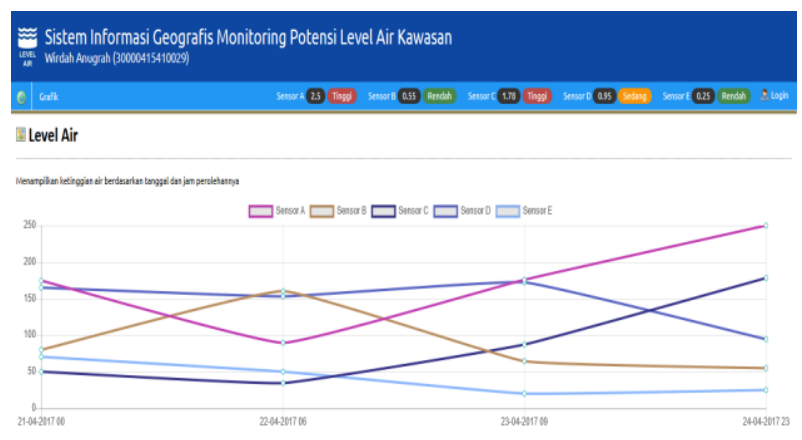

Fig. 5. Page of user graph

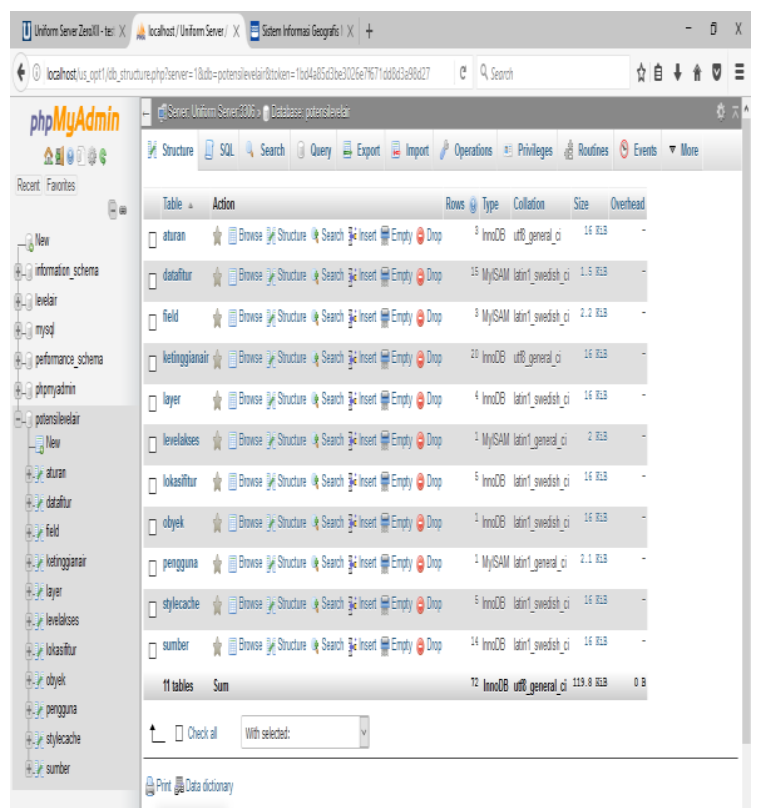

Fig. 6. View of database GIS

Water level data obtained from sensor acquisition results are stored into the database and then processed by using a rule-based system based on the Regulation of the Head of National Agency for Disaster Management Number 02 Year 2012 on General Guidelines for 
Disaster Risk Assessment. In accordance with these rules can be determined the rules, as follows:

$$
\begin{aligned}
& \text { \$ Level Air } \\
& \text { if Level Air }<0.76 \mathrm{~m} \\
& \text { then potential of area }=\text { Low } \\
& \text { if Level Air }>0.76 \mathrm{~m} \text { and Level Air }<1.5 \mathrm{~m} \\
& \text { then potential of area }=\text { Medium } \\
& \text { if Level Air }>1.5 \mathrm{~m} \\
& \text { then potential of area }=\text { High }
\end{aligned}
$$

In the GIS process of data collection coordinates by

\begin{tabular}{|c|c|c|c|}
\hline No. & Coordinates & Location & Sensor \\
\hline 1. & $\begin{array}{l}-7.030024, \\
110.464439\end{array}$ & $\begin{array}{c}\text { Banjir Kanal } \\
\text { Timur }\end{array}$ & $\mathrm{A}$ \\
\hline 2. & $\begin{array}{l}-7.055238, \\
110.380669\end{array}$ & $\begin{array}{c}\text { Banjir Kanal } \\
\text { Barat }\end{array}$ & $\mathrm{B}$ \\
\hline 3. & $\begin{array}{l}-7.004808 \\
110.352516\end{array}$ & Silandak & $\mathrm{C}$ \\
\hline 4. & $\begin{array}{l}-7.038883 \\
110.319557\end{array}$ & Plumbon & $\mathrm{D}$ \\
\hline 5. & $\begin{array}{l}-7.065460 \\
110.463753\end{array}$ & Babon & $\mathrm{E}$ \\
\hline
\end{tabular}
mapping or retrieving from Google Map as much as 5 (five) locations in Semarang City, the data as input data for data processing which will be used for monitoring the potential of water level in the area that has been determined. The coordinate data can be seen in Table 1 .

Table 1. Data of Coordinates

\section{Conclusions}

GIS for monitoring the water level potential of the built area is able to behave intelligently by acquiring water level data, time data, and sensor location data which is then processed with rule based system whose source of knowledge is the regulation of Head of National Disaster Management Agency Number 02 of 2012 About General Guidelines Disaster Risk Assessment. In accordance with the regulation, the established rule if the water level is $<0.76 \mathrm{~m}$ then the area is potentially low, if the Water level $>0.76 \mathrm{~m}$ to $<1.5 \mathrm{~m}$ then the area is potentially moderate, and if the water level $>1.5 \mathrm{~m}$ then the area is potentially high.
Coordinate data on GIS was taken with mapping from google map, ie coordinate point -7.030024, 110.464439 at east flood canal location, -7.055238, 110.380669 at western canal flood location, -7.004808, 110.352516 at silandak location, -7.038883, 110.319557 at plumbon location, And -7.065460, 110.463753 at the baboon location. GIS is also processed through mapping which results in maps, layers, charts, altitude values, potential status, and location of sensors that are realtime.

\section{References}

1. M. Xiaocong, Q. X. Jiao, and S. Shaohong, International Conference on Intelligent HumanMachine Systems and Cybernetics, Vol.2 , $365-$ 368, IEEE, (2015)

2. K. Lukasiewicz, K. Teymourian, and A. Paschke, The Semantic Web: ESWC 2014 Satellite Events - Lecture Notes in Computer Science 8798, 401406, (2014)

3. H. Yingzhan, H. Xuemei, and Y. Xingzhi, International Workshop on Intelligent Systems and Applications (ISA), 1- 4, IEEE, (2011)

4. E. Prahasta, Build a Web-based GIS Application with MapServer, Publisher Informatics, Bandung, (2006)

5. E. Prahasta, Geographic Information System: Basic Concepts (Geodesy \& Geomatical Perspectives), Publisher Informatics, Bandung, (2005)

6. Riyanto, P. E. Putra, H. Indelarko, Application Development of Geographic Information System, Publisher Media Style, Yogyakarta, (2009)

7. A. Abraham, Rule-based Expert Systems, Handbook of Measuring System Design, Oklahoma State University, USA, (2005)

8. A. Sulistiyo, and S. Suryono, Youngster Physics Journal, Vol.5, No.2, 43 - 50, (2016)

9. R. Pressman, Software Engineering: A Practitioner is Approach, New York: McGrawHill, (2001) 